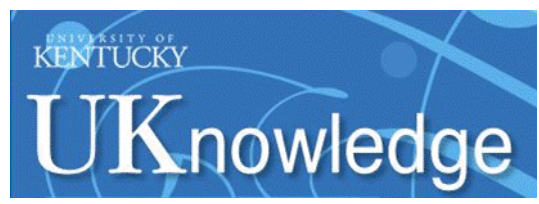

University of Kentucky

UKnowledge

5-8-2017

\title{
Use of Annual Phosphorus Loss Estimator (APLE) Model to Evaluate a Phosphorus Index
}

\author{
Nicole M. Fiorellino \\ Chesapeake College \\ Joshua M. McGrath \\ University of Kentucky, josh.mcgrath@uky.edu \\ Peter A. Vadas \\ USDA Agricultural Research Service \\ Carl H. Bolster \\ USDA Agricultural Research Service \\ Frank J. Coale \\ USDA Agricultural Research Service
}

Follow this and additional works at: https://uknowledge.uky.edu/pss_facpub

Part of the Environmental Sciences Commons, and the Soil Science Commons

Right click to open a feedback form in a new tab to let us know how this document benefits you.

\section{Repository Citation}

Fiorellino, Nicole M.; McGrath, Joshua M.; Vadas, Peter A.; Bolster, Carl H.; and Coale, Frank J., "Use of Annual Phosphorus Loss Estimator (APLE) Model to Evaluate a Phosphorus Index" (2017). Plant and Soil Sciences Faculty Publications. 132.

https://uknowledge.uky.edu/pss_facpub/132

This Article is brought to you for free and open access by the Plant and Soil Sciences at UKnowledge. It has been accepted for inclusion in Plant and Soil Sciences Faculty Publications by an authorized administrator of UKnowledge. For more information, please contact UKnowledge@lsv.uky.edu. 


\section{Use of Annual Phosphorus Loss Estimator (APLE) Model to Evaluate a Phosphorus Index}

Digital Object Identifier (DOI)

https://doi.org/10.2134/jeq2016.05.0203

\section{Notes/Citation Information}

Published in Journal of Environmental Quality, v. 46, no. 6, p. 1380-1387.

Copyright (C) American Society of Agronomy, Crop Science Society of America, and Soil Science Society of America.

This is an open access article distributed under the terms of the CC BY-NC-ND license (http://creativecommons.org/licenses/by-nc-nd/4.0/). 


\title{
Use of Annual Phosphorus Loss Estimator (APLE) Model to Evaluate a Phosphorus Index
}

\author{
Nicole M. Fiorellino, Joshua M. McGrath, Peter A. Vadas, Carl H. Bolster, and Frank J. Coale
}

\begin{abstract}
The Phosphorus (P) Index was developed to provide a relative ranking of agricultural fields according to their potential for $\mathrm{P}$ loss to surface water. Recent efforts have focused on updating and evaluating $\mathrm{P}$ Indices against measured or modeled P loss data to ensure agreement in magnitude and direction. Following a recently published method, we modified the Maryland P Site Index (MD-PSI) from a multiplicative to a component index structure and evaluated the MD-PSI outputs against P loss data estimated by the Annual P Loss Estimator (APLE) model, a validated, fieldscale, annual $\mathrm{P}$ loss model. We created a theoretical dataset of fields to represent Maryland conditions and scenarios and created an empirical dataset of soil samples and management characteristics from across the state. Through the evaluation process, we modified a number of variables within the MD-PSI and calculated weighting coefficients for each P loss component. We have demonstrated that our methods can be used to modify a P Index and increase correlation between P Index output and modeled $\mathrm{P}$ loss data. The methods presented here can be easily applied in other states where there is motivation to update an existing P Index.
\end{abstract}

\section{Core Ideas}

- Our methods expanded upon methods developed by Bolster to modify and evaluate PIs.

- Our methods provide practical guidance to other states for modification of Pls.

- A theoretical dataset was simulated to represent geographical conditions in Maryland.

- Removal of categorical variables and weights increased PI and P loss correlation.

- Fertilizer and subsurface components should be evaluated like surface components.
Copyright $\odot$ American Society of Agronomy, Crop Science Society of America, and Soil Science Society of America. 5585 Guilford Rd., Madison, WI 53711 USA.

All rights reserved.

J. Environ. Qual. 46:1380-1387 (2017)

doi:10.2134/jeq2016.05.0203

This is an open access article distributed under the terms of the CC BY-NC-ND

license (http://creativecommons.org/licenses/by-nc-nd/4.0/)

Supplemental material is available online for this article.

Received 31 May 2016.

Accepted 11 Apr. 2017

*Corresponding author (nfiorellino@chesapeake.edu).
$\mathrm{P}$ HOSPHORUS (P) loss to surface waters from point or nonpoint sources can contribute to eutrophication, which is a major water quality problem globally (King et al., 2014). Eutrophication is an important issue in the Chesapeake Bay Watershed and especially in the state of Maryland, which surrounds the Chesapeake Bay (Boynton, 2000). Agriculture in the bay watershed has been named as one of the primary nonpoint sources of P leading to eutrophication (Sharpley et al., 2003).

Often, a small proportion of the agricultural landscape that is hydrologically connected and has sources for P loss (e.g., high soil $\mathrm{P}$ concentrations) is responsible for the majority of $\mathrm{P}$ loss to surface water (Gburek and Sharpley, 1998; Sharpley et al., 2003). The P Index was developed as a tool to identify agricultural fields that have a high risk of $\mathrm{P}$ loss due to the coinciding presence of $\mathrm{P}$ sources and transport pathways (Lemunyon and Gilbert, 1993; Nelson and Shober, 2012; Sharpley et al., 2012). Additionally, P Indices can help guide producers in the adoption of management practices to reduce the risk of $\mathrm{P}$ loss. The $\mathrm{P}$ Index was designed to be user friendly by using simple calculations and requiring minimal input data (Lemunyon and Gilbert, 1993; Gburek et al., 2000; Djodjic and Bergström, 2005).

Phosphorus Indices exist in different versions across the United States, with differences in mathematical formulations, input variables, and how the P Index output is interpreted for management (Sharpley et al., 2003). It has been shown that multiple versions of $\mathrm{P}$ Indices can estimate different $\mathrm{P}$ loss risk and suggest adoption of different management practices for the same field (Osmond et al., 2012). This has prompted a call for more thorough assessment of P Indices (Sharpley et al., 2012), ideally by using local measured P loss data to assess how well P Index output agrees in magnitude and direction with measurements. However, when local P loss data are not available, P Index

N.M. Fiorellino, Agriculture Dep., Chesapeake College, 1000 College Circle, Wye Mills, MD 21679; J.M. McGrath, Dep. of Plant and Soil Sciences, Univ. of Kentucky, N122-P Ag Science North, Lexington, KY 40546; P.A. Vadas, USDA-ARS, 1925 Linden Dr. West, Madison, WI 53706; C.H. Bolster, USDA-ARS, 2413 Nashville Rd. B-5, Bowling Green, KY 42101. F.J. Coale, Dep. of Environmental Science and Technology, Univ. of Maryland, 4065 Campus Dr., College Park, MD 20742. Assigned to Associate Editor Deanna Osmond.

Abbreviations: $\mathrm{AM}$, amendment management factor; $\mathrm{AM}_{\mathrm{r}}$, runoff application method factor; $\mathrm{AM}_{\mathrm{v} .2^{\prime}}$ application method factor for PMT-2; APLE, Annual Phosphorus Loss Estimator model; comp-PSI, component version of the Maryland Phosphorus Site Index; DP, dissolved phosphorus; $\mathrm{DPS}_{\mathrm{M3}^{\prime}}$ degree of phosphorus saturation ratio estimated from Mehlich-3 elements; FIV, University of Maryland Phosphorus Fertility Index Value; M3P, Mehlich-3 extractable phosphorus; MD-PSI, Maryland Phosphorus Site Index; PMT-2, Phosphorus Management Tool 2; RUSLE, Revised Universal Soil Loss Equation; SCS, Soil Conservation Service; SED, sediment transport factor; SM, soil management factor; SR, surface runoff transport risk factor; TP, total phosphorus. 
outputs can be compared with $\mathrm{P}$ loss as estimated by a computer model that has been shown to reliably estimate field-scale P loss (Bolster, 2011; Sharpley et al., 2011).

The Maryland P Site Index (MD-PSI) has been part of nutrient management planning in Maryland since 2002 (Coale et al., 2002). Datasets of measured, field-scale P loss that represent the wide variations in landscapes and agricultural practices are scarce in Maryland (Angle et al., 1984; Kleinman et al., 2007; Vadas et al., 2007). Thus, assessment of the MD-PSI was dependent on the use of modeled P loss data, in accordance with the recommendations of Sharpley et al. (2011). Bolster et al. (2012) suggested a method for using modeled $\mathrm{P}$ loss data to assess a state $\mathrm{P}$ Index. Those authors used the Annual P Loss Estimator (APLE; Vadas et al., 2009; Vadas, 2012) to estimate P loss data to evaluate $\mathrm{P}$ Index outputs and recommend changes to the P Index so its output agrees better with APLE P loss estimates.

Our objectives in the current study were (i) to use the proofof-concept method presented by Bolster et al. (2012) to modify the MD-PSI in accordance with the recommendations presented above by Sharpley et al. (2011), and (ii) by doing so, to provide guidance to other states interested in using this method to modify their P Indices.

\section{Materials and Methods}

\section{Description of APLE and MD-PSI}

The APLE model estimates annual, field-scale total P (TP, $\mathrm{kg} \mathrm{ha}^{-1}$ ) loss in surface runoff by summing dissolved P (DP) loss from manure $\left(\mathrm{DP}_{\text {manure }}\right)$, soil $\left(\mathrm{DP}_{\text {soil }}\right)$, and fertilizer $\left(\mathrm{DP}_{\text {fertilizer }}\right)$ and particulate-bound $\mathrm{P}\left(\mathrm{P}_{\text {sediment }}\right)$ lost through soil erosion (Eq. 1]) (Vadas et al., 2009; Vadas, 2012). Unlike process-based models, APLE is an empirically based model that relies on relationships between modeled P loss and measured loss data and does not account for the processes governing P loss in the landscape (Bolster et al., 2017). The empirical nature of the APLE model limits the use of APLE to locations where the data used to develop the model were collected; however this allows APLE to require minimal input data and training for its use and, in turn, allows for widespread ease of use.

Vadas et al. (2009) evaluated APLE against measured P loss data for a broad range of field management practices and conditions. That evaluation included P loss data from one study in Maryland (Angle et al., 1984), as well as studies conducted in North Carolina for similar soil types and climate conditions (Westerman et al., 1985; Westerman et al., 1987; Kleinman et al., 2007; Edgell et al., 2015). Figure 1 shows the relationship between total P loss estimated by APLE and measured TP loss from the four studies cited, as well as an additional study by Kleinman et al. (2007) conducted in Maryland, indicating that APLE appropriately estimated P loss in Maryland conditions. Moreover, Bolster et al. (2017) found that APLE provided slightly more accurate estimates of P loss than the Texas Best Management Practice Evaluation Tool, a more complex daily time-step model. This indicated that the use of a more complex process-based model may not generate more accurate estimates of $\mathrm{P}$ loss than a more user-friendly empirical model. These results suggest that APLE can reliably estimate field-scale P loss for Maryland conditions and, despite being user friendly and empirically based, it is appropriate for evaluation of the MD-PSI, as suggested by Bolster et al. (2012).
The APLE model does not include subsurface $P$ loss pathways or estimates of $\mathrm{P}$ delivery beyond the edge of field. We recognize that subsurface DP transport is a dominant $P$ loss pathway from ditch drained fields on the coastal plain of the Delmarva Peninsula (Vadas et al., 2007). This P loss component was included in the MD-PSI and warrants similar evaluation using an appropriate P loss model. However, the APLE model was used in the present study; therefore, the subsurface component of the MD-PSI was not included in the present evaluation.

Moreover, DP loss from fertilizer was also omitted from this assessment, as the empirical dataset did not contain sites with a planned fertilizer P application. This is typical in Maryland, where fertilizer $\mathrm{P}$ would not be applied to fields with high soil $\mathrm{P}$ concentration. Therefore the APLE TP loss estimate used for the present evaluation is:

$\mathrm{APLE} \mathrm{TP}=\mathrm{DP}_{\text {manure }}+\mathrm{DP}_{\text {soil }}+\mathrm{P}_{\text {sediment }}$

Required model inputs for the $\mathrm{DP}_{\text {manure }}$ calculation include annual rainfall, annual runoff, manure and fertilizer application rates and methods, and associated $\mathrm{P}$ properties. Inputs for $\mathrm{DP}_{\text {soil }}$ include Mehlich-3 soil P (M3P, $\mathrm{mg} \mathrm{kg}^{-1}$ ) and annual runoff. Inputs for $\mathrm{P}_{\text {sediment }}$ include M3P $\left(\mathrm{mg} \mathrm{kg}^{-1}\right)$, soil clay and organic matter content (\%), and annual sediment loss.

Following recommendations from Bolster et al. (2012), the formulation of the MD-PSI used in this evaluation represented a component format similar to that of APLE. We refer to the MD-PSI formulation here as the component version of the MD-PSI (comp-PSI). The MD comp-PSI equation was structured as follows:

comp-PSI $=$ Particulate + SoilDP + ManureDP

where

Particulate $=$ SED $\times$ FIV

SoilDP $=\mathrm{SR} \times \mathrm{DPS}_{\mathrm{m} 3}$

ManureDP $=\mathrm{SR} \times\left(\sum \mathrm{PSC} \times\right.$ manure $\left._{2} \mathrm{O}_{5} \times \mathrm{AM}_{\mathrm{r}}\right)$

where $\mathrm{SED}$ is the sediment transport factor with possible values of 2, 4, 6, 8, and 10; FIV is the University of Maryland P Fertility Index Value; $S R$ is the surface runoff transport risk factor

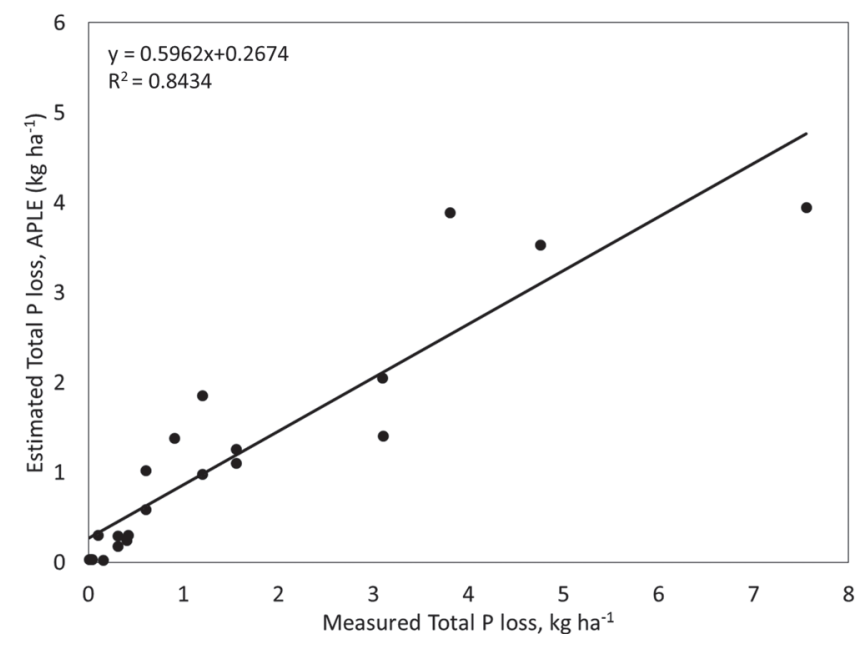

Fig. 1. Measured total phosphorus (P) loss from Maryland and surrounding states versus modeled total $\mathrm{P}$ loss estimated by the Annual P Loss Estimator (APLE) model. Regression is significant at $P<0.0001$. 
(Supplemental Table S4); DPS $_{\mathrm{M} 3}$ is the degree of P saturation ratio (Sims et al., 2002) using Mehlich-3 extractable concentrations of $\mathrm{P}, \mathrm{Fe}$, and $\mathrm{Al}$; PSC is the $\mathrm{P}$ source coefficient for each $\mathrm{P}$ amendment; manure $\mathrm{P}_{2} \mathrm{O}_{5}$ is the quantity of $\mathrm{P}_{2} \mathrm{O}_{5}$ applied in manure $\left(\mathrm{kg} \mathrm{P} \mathrm{ha}^{-1}\right)$; and $\mathrm{AM}_{\mathrm{r}}$ is runoff application method factor with possible values of $0,0.2,0.4,0.6$, and 0.8 (Supplemental Table S5). The FIV is a unitless index value used in Maryland to represent soil-test $P$ concentrations from selected soil extracts (such as Bray, Mehlich-1, or Mehlich-3) (McGrath, 2006). Phosphorus FIV of 150 is approximately equal to 122 to $142 \mathrm{mg}$ $\mathrm{kg}^{-1} \mathrm{M} 3 \mathrm{P}$. The $\mathrm{P}$ loss components of the comp-PSI corresponded to the P loss outputs of APLE (Particulate: $P_{\text {sediment }}$ SoilDP:DP ${ }_{\text {soil' }}$ and ManureDP:DP $P_{\text {manure }}$ ).

\section{Creation of Independent Datasets for MD comp-PSI Evaluation}

The first step in our evaluation was to generate datasets as input for both APLE and the MD comp-PSI. Following the methods of Bolster et al. (2012), we generated two independent datasets containing site, management, and $\mathrm{P}$ source data representing Maryland farm fields. The first was a "theoretical" dataset of possible values for these variables and was used to identify where modifications to the comp-PSI equation might be needed to agree with APLE output. The second, "empirical" dataset consisted of actual site information collected from farms across Maryland and was used to evaluate the modifications made to the comp-PSI.

Our theoretical dataset represented combinations of physical and management conditions that could potentially exist in Maryland fields. The dataset initially consisted of 15,000 representative "fields" generated using SAS 9.3 (SAS Institute, 2009). Variables necessary to calculate MD-PSI and APLE output were included for each field (Supplemental Tables S1-S3). Values for some variables were randomly assigned using a uniform distribution within a predefined range to ensure an equal probability of being present throughout the dataset (Bolster, 2011). The range for each variable was defined using literature values or the range observed in the empirical dataset (Supplemental Tables S2 and S3). We obtained data for each soil type by county from the Soil Survey Geographic Database (SSURGO) and $30 \mathrm{yr}$ of daily precipitation data by Maryland county from the ParameterElevation Regressions on Independent Slopes Model (PRISM) Climate Group at Oregon State University (PRISM Climate Group, 2015). Soil erosion was estimated using RUSLE (Revised Universal Soil Loss Equation), and annual runoff was estimated using the Soil Conservation Service (SCS) Curve Number method (USDA-SCS, 1972; Renard et al., 1997). The soil erosion and runoff values were used as input for APLE calculations. A full description of value assignment to each variable is presented in the Supplemental Material, as well as a detailed description of the calculation of runoff for the theoretical dataset.

For the empirical dataset, we collected physical data and soil from 382 agricultural fields across Maryland between 2011 and 2012. Physical data included site characteristics and field management practices required as input for APLE and the compPSI (Supplemental Tables S2 and S3). Clinometers were used to determine field slope. Soil samples were collected using a hand sample probe ( 0 - to $20-\mathrm{cm}$ depth). We collected a minimum of 15 subsamples per field and combined them into one composite soil sample. Sampled fields ranged in size from 0.2 to 45 ha. Soils were dried $\left(60^{\circ} \mathrm{C}\right)$ and ground $(2 \mathrm{~mm})$ for Mehlich-3 (Mehlich, 1984) extraction (1:10 soil/ $0.2 \mathrm{M} \mathrm{CH}_{3} \mathrm{COOH}+0.25 \mathrm{M} \mathrm{NH}_{4} \mathrm{NO}_{3}+$ $0.015 \mathrm{M} \mathrm{NH}_{4} \mathrm{~F}+0.13 \mathrm{M} \mathrm{HNO}_{3}+0.0001 \mathrm{M}$ ethylenediaminetetraacetic acid [EDTA]). Phosphorus, iron (M3Fe), and aluminum $(\mathrm{M} 3 \mathrm{Al})$ concentrations in the extracts were determined by inductively coupled plasma atomic emission spectroscopy (ICP-AES). Mehlich-3 P saturation ratio $\left(\mathrm{PSR}_{\mathrm{M} 3}\right.$, Eq. [3]) was calculated using the molar concentrations of $\mathrm{M} 3 \mathrm{P}, \mathrm{M} 3 \mathrm{Fe}$, and $\mathrm{M} 3 \mathrm{Al}$ and then used to estimate the ammonium oxalate-equivalent DPS $\left(\mathrm{DPS}_{\mathrm{M} 3}\right)$ using the method of Sims et al. (2002):

$$
\mathrm{DPS}_{\mathrm{M} 3}=\frac{\mathrm{PSR}_{\mathrm{M} 3}+0.19}{0.0042}
$$

where

$$
\mathrm{PSR}_{\mathrm{M} 3}=\frac{\mathrm{M} 3 \mathrm{P}}{\mathrm{M} 3 \mathrm{Fe}+\mathrm{M} 3 \mathrm{Al}}
$$

The comp-PSI is required on fields where producers plan to apply $\mathrm{P}$ and where P-FIV exceeds 150 . Some fields in the empirical dataset did not have a planned $\mathrm{P}$ application or were below the threshold P-FIV value. In these cases, we randomly assigned FIV using a uniform distribution from 150 to 913 (the maximum FIV present in the empirical dataset) and calculated M3P using the conversion from McGrath (2006). When a P application was not planned, we assumed a manure application following methods for the theoretical dataset.

In some instances, values for variables in the theoretical dataset fell within defined ranges but, when combined, produced values for RUSLE or DPS ${ }_{\mathrm{M} 3}$ greater than commonly observed in Maryland. If estimated sediment loss was $>18 \mathrm{Mg} \mathrm{ha}^{-1}\left(8 \mathrm{t} \mathrm{ac}^{-1}\right)$ or $\mathrm{DPS}_{\mathrm{M} 3}$ values were $>120 \%$, they were eliminated from the theoretical dataset. After elimination, the final theoretical dataset contained 10,249 observations. Fields with RUSLE values $>18 \mathrm{Mg} \mathrm{ha}^{-1}$ were also eliminated from the empirical dataset (final $n=354$ ).

\section{Output Comparison and Development of Weighting Factors}

For each field, we used data from the theoretical dataset to calculate comp-PSI values and estimate P loss with APLE. We then compared comp-PSI and APLE output by calculating Pearson correlation coefficients $(r)$ using the CORR procedure in SAS 9.3 (SAS Institute, 2009). We used this process to develop modifications for the comp-PSI so its output would better agree with APLE $P$ loss estimates. This entailed comparison between comp-PSI components and APLE output (e.g., SoilDP from the comp-PSI and $\mathrm{DP}_{\text {soil }}$ from APLE), as well as the final comp-PSI score and TP loss predicted by APLE. Regression analysis using the REG procedure in SAS 9.3 (SAS Institute, 2009) was used to calculate slope of the regression line between TP estimated by APLE and TP comp-PSI score for a subset of data points in the theoretical dataset.

Following modifications to the comp-PSI components, weighting coefficients $(W)$ were calculated for each of the P loss components in the modified comp-PSI. Following the equation derived from Bolster et al. (2012), the difference between the logarithm of the APLE P loss component score and the 
logarithm of the comp-PSI component score was calculated for all fields in the theoretical dataset. The weighting factor was then determined as the exponent of the mean of the difference of the component outputs:

$W=e^{\frac{\sum(\log \mathrm{APLE}-\log c o m p-\mathrm{PSI})}{n}}$

Weighting factors were intended to ensure that relative $\mathrm{P}$ loss from the different comp-PSI components agreed with APLE.

Once all modifications were made and weighting factors were calculated for the components of the modified comp-PSI equation, the resulting equation was named the $\mathrm{P}$ Management Tool 2 (PMT-2). Additional management factors were included in the PMT-2 to promote the use of Maryland-specific beneficial management practices. Although these factors did not have parallel variables in APLE, we determined that the present study was the appropriate outlet to include new management factors in the PMT-2 equation and evaluate their use. The final PMT-2 score was calculated for all fields in the empirical dataset and then correlated to its corresponding APLE output.

\section{Results and Discussion}

\section{MD comp-PSI Revisions Using Theoretical Data and APLE Particulate Component}

The particulate P loss component of the comp-PSI equation was strongly correlated to the sediment $\mathrm{P}$ loss estimated by APLE for the theoretical dataset $\left(r=0.84^{* * *}\right.$, Fig. 2a), but the relationship exhibited a stepwise pattern. The strong correlation resulted from similar variables being used in both the comp-PSI and APLE, which rely on M3P and RUSLE erosion calculations to estimate particulate-bound P loss. The categorical nature of the SED variable in the comp-PSI caused the stepwise pattern observed in Fig. 2a. Because particulate P loss is actually a continuous function of erosion rate, we eliminated this stepwise pattern by replacing the categorical SED factor in the comp-PSI with the numerical estimate of sediment loss predicted by RUSLE (in tons $\mathrm{ac}^{-1} \mathrm{yr}^{-1}$ ). Phosphorus Indices across the United States commonly use RUSLE to estimate particulate-bound P loss (Sharpley et al., 2003). This modification and calculated weighting factor $(W=0.154)$ improved the correlation coefficient between the comp-PSI particulate component and particulate P loss estimated by APLE $\left(r=0.92^{* * *}\right.$, Fig. $\left.2 \mathrm{~b}\right)$. This demonstrates a potential challenge in having P Index scores relate well to measured or modeled P loss data when a P Index uses categorical weighting factors, which is common. The calculated weighting factor $(W)$ also decreased the range of values for the PMT-2 particulate score from 6000 to 800 . Equations for particulate P loss for APLE, comp-PSI, and PMT-2 are detailed in Table 1.

\section{Soil Dissolved P Component}

A data cloud with a general linear trend was observed for the correlation between the SoilDP component of the comp-PSI and soil DP loss estimated by APLE for the theoretical dataset $\left(r=0.64^{* * *}\right.$, Fig. 3a). Despite the general correlation, there were distinct groups of data present in Fig. 3 a due to the categorical SR factor in the comp-PSI. Because soil DP loss is actually a continuous function of runoff, we replaced the categorical SR factor used to index transport risk in the SoilDP component, with
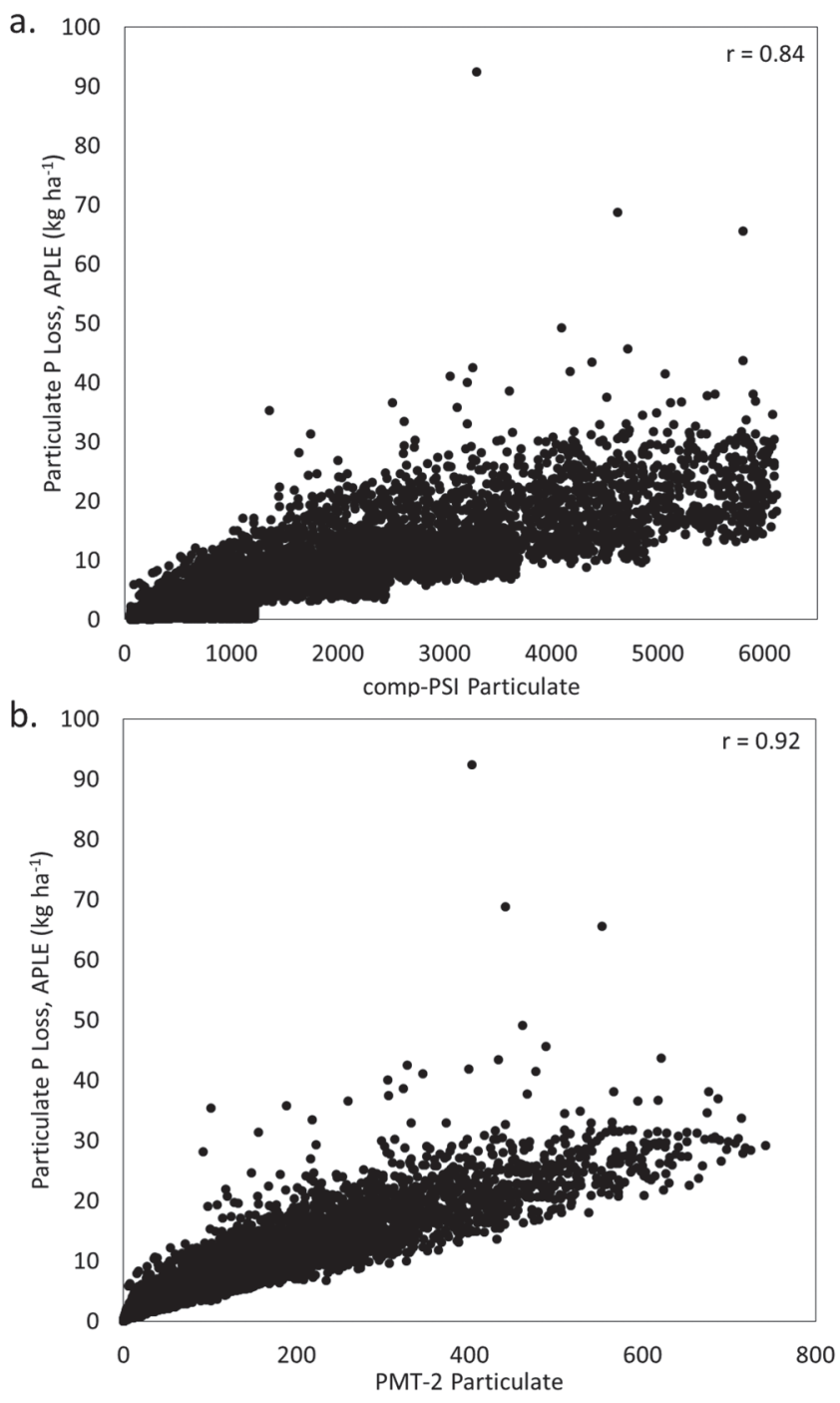

Fig. 2. Modeled particulate phosphorus (P) loss in $\mathrm{kg} \mathrm{ha}^{-1}$ as estimated by the Annual Phosphorus Loss Estimator (APLE) model versus (a) the particulate component of the component version of the Maryland P Site Index (comp-PSI) and (b) the particulate component of the P Management Tool 2 (PMT-2) for the theoretical dataset $(n=$ 10249). Correlations are significant at $P<0.0001$.

annual runoff $(\mathrm{mm})$ calculated using the SCS Curve Number method (USDA-SCS, 1972). These runoff values were the same as used for APLE input. We retained DPS ${ }_{\mathrm{M} 3}$ as the source factor for the SoilDP component in the PMT-2; however, a conversion factor of 0.0259 was included to relate soil DPS ${ }_{\mathrm{M} 3}$ to DP concentrations $\left(\mathrm{mg} \mathrm{P} \mathrm{L}^{-1}\right)$ in runoff, as Vadas et al. (2005b) determined by regression. Modifying the comp-PSI SoilDP component resulted in a strong linear correlation between PMT-2 and soil DP estimated by APLE ( $r=0.99^{* * *}$, Fig. $\left.3 \mathrm{~b}\right)$. The modifications to the SoilDP component and the inclusion of the weighting factor calculated using Eq. [4] $(W=0.67)$ decreased the range of values for the PMT-2 SoilDP score (Fig. 3b) from 1750 to 6 for the PMT-2 SoilDP score. Equations for soil DP loss for APLE, comp-PSI, and PMT-2 are detailed in Table 1.

\section{Manure Dissolved P Component}

Initially, a poor correlation was observed between the compPSI ManureDP component and the APLE-estimated DP loss from manure $\left(r=0.09^{* * *}\right.$, Fig. 4a). This indicated that the compPSI approach poorly represented the risk of P loss from applied 
Table 1. Variables included for each phosphorus (P) loss component equation (Particulate, SoilDP [dissolved P], ManureDP) within the Annual P Loss Estimator (APLE), component version of the Maryland P Site Index (comp-PSI) and the final P Management Tool 2 (PMT-2) equation.

\begin{tabular}{|c|c|c|c|}
\hline \multirow{2}{*}{ Equation } & \multicolumn{3}{|c|}{ Componentst } \\
\hline & Particulate & SoilDP & ManureDP \\
\hline APLE & $\begin{array}{l}\text { RUSLE } \times \text { soil total } P \times \\
\text { erosion enrichment ratio }\end{array}$ & $\begin{array}{c}\text { Soil labile } \mathrm{P} \times \text { extraction coefficient } \times \\
\text { annual runoff }\end{array}$ & $\begin{array}{l}\text { (Rainfall/Runoff) } 1.25 \times \text { manure } \mathrm{P}_{2} \mathrm{O}_{5} \times \\
\text { WEP\% } \times \text { manure incorporated }\end{array}$ \\
\hline comp-PSI & SED $\times$ FIV & $\mathrm{SR} \times \mathrm{DPS}_{\mathrm{M} 3}$ & $\mathrm{SR} \times \Sigma\left(\mathrm{PSC} \times\right.$ manure $\left.\mathrm{P}_{2} \mathrm{O}_{5} \times \mathrm{AM}_{\mathrm{r}}\right)$ \\
\hline PMT-2 & $0.155($ RUSLE $\times 2.24) \times$ FIV & $\begin{array}{l}0.67(\text { Runoff } \times 0.01) \times \\
\left(0.0259 \times \mathrm{DPS}_{\mathrm{M} 3}\right) \times \mathrm{SM}\end{array}$ & $\begin{array}{c}\text { 1.11(Rainfall/Runoff })^{1.25} \times \text { manure } \mathrm{P}_{2} \mathrm{O}_{5} \times \\
\text { WEP\% } \times \mathrm{AM}_{\mathrm{v} .2} \times \mathrm{AM}\end{array}$ \\
\hline
\end{tabular}

† RUSLE, Revised Universal Soil Loss Equation; WEP\%, percentage of water-extractable P; SED, sediment transport factor; FIV, University of Maryland P Fertility Index Value; $\mathrm{SR}$, surface runoff transport risk factor; $\mathrm{DPS}_{\mathrm{M}^{\prime}}$ degree of $\mathrm{P}$ saturation ratio estimated from Mehlich-3 elements; $\mathrm{PSC}$, $\mathrm{P}$ source coefficient; $\mathrm{AM}_{\mathrm{r}^{\prime}}$ runoff application method factor; SM, soil management factor; $\mathrm{AM}_{\mathrm{v}, 2}$, application method factor for PMT-2; AM, amendment management factor.

manure when compared with APLE manure DP output. To be more consistent with the APLE approach, we replaced the categorical SR variable in the comp-PSI ManureDP component with the ratio of runoff to rainfall raised to the power of 1.25 , as is documented for APLE (Vadas et al., 2005a; Vadas, 2012).
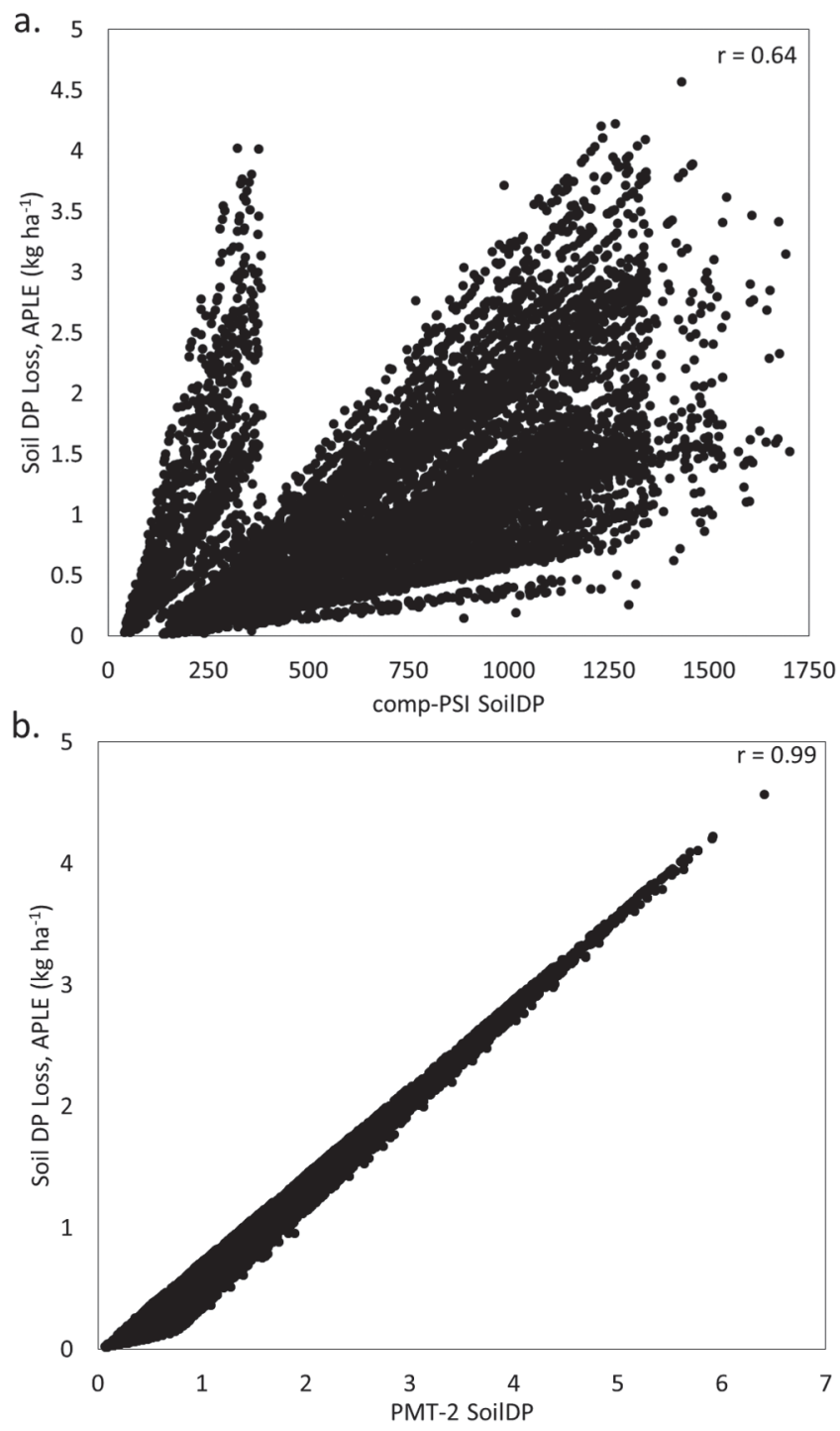

Fig. 3. Modeled soil dissolved phosphorus (DP) loss in $\mathrm{kg} \mathrm{ha}^{-1}$ as estimated by the Annual Phosphorus Loss Estimator (APLE) model versus (a) the SoilDP component of the component version of the Maryland P Site Index (comp-PSI) and (b) the SoilDP component of the P Management Tool 2 (PMT-2) for the theoretical dataset $(n=$ 10249). The unique weighting coefficients included in PMT-2 modified the scale of the $x$-axis from (a) to (b). Correlations are significant at $P<0.0001$.
Because we adopted the APLE approach for the ManureDP component instead of a categorical SR variable, we also replaced the source factor for the comp-PSI ManureDP component (PSC $\times$ manure $\mathrm{P}_{2} \mathrm{O}_{5} \times \mathrm{AM}_{\mathrm{r}}$ ) by the quantity of $\mathrm{P}$ applied to a field multiplied by the proportion of manure TP that is water extractable (WEP\%), as this is the quantity of $\mathrm{P}$ that is dissolved from
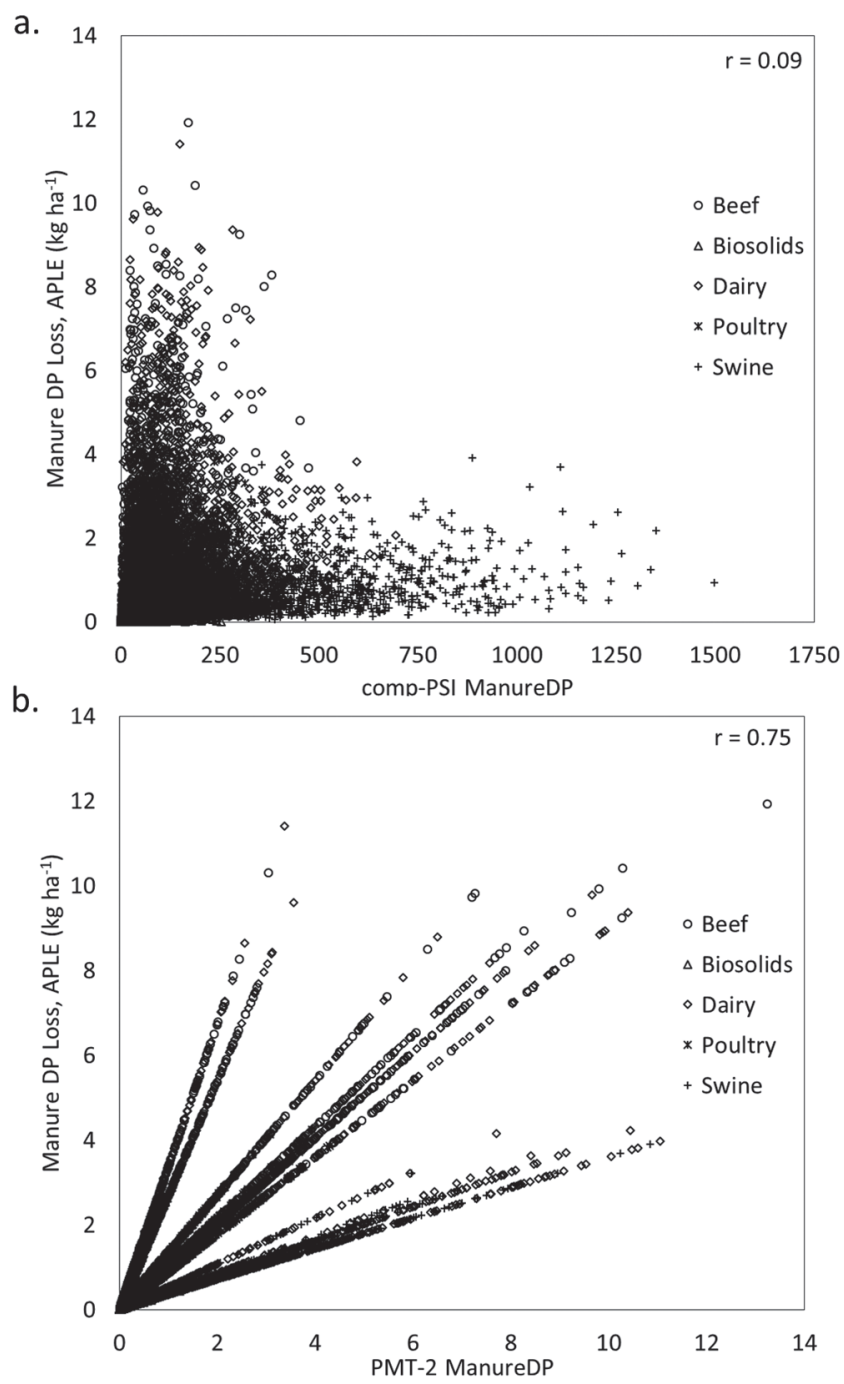

Fig. 4. Modeled manure dissolved phosphorus (DP) loss in $\mathrm{kg} \mathrm{ha}^{-1}$ as estimated by the Annual Phosphorus Loss Estimator (APLE) model versus (a) the ManureDP component of the component version of the Maryland P Site Index (comp-PSI) by manure type and (b) the ManureDP component of the P Management Tool 2 (PMT-2) by manure type for the theoretical dataset $(n=10249)$. The unique weighting coefficients included in PMT-2 modified the scale of the $x$-axis from (a) to (b). Correlations are significant at $P<0.0001$. 
manure during a rain event (Vadas et al., 2005a). The manure source was then multiplied by the application method factor $\left(\mathrm{AM}_{\mathrm{v}, 2}\right.$, Supplemental Table S6), which represented amendment application practices and was similar to the $\mathrm{AM}_{\mathrm{r}}$ factor in the comp-PSI. This was the only categorical factor that remained in the comp-PSI equation and was included for the comparison of the ManureDP component and manure DP predicted by APLE. This categorical factor was responsible for the straight-lines clustering of data observed in Fig. 4b. The amendment management factor (AM) was included in the final PMT-2 equation and has possible values of 0.5 and 1 . This factor was designed to incorporate additional field management practices that producers could implement, namely the use drainage water filtration to minimize $\mathrm{P}$ loss. Few producers in Maryland are using the practice, and it was not included in the evaluation.

The modifications to the ManureDP component resulted in a larger coefficient of correlation between the ManureDP component of the PMT-2 and manure DP loss estimated by APLE $\left(r=0.75^{* * *}\right.$, Fig. $\left.4 \mathrm{~b}\right)$. The modifications and the inclusion of the weighting factor calculated using Eq. [4] $(W=1.11)$ decreased the range of values for the PMT-2 ManureDP component from 1500 to $\sim 12$. The equations for manure DP for APLE, compPSI, and PMT-2 are detailed in Table 1.

The adjusted range of SoilDP and ManureDP values appear to more similarly capture the relative proportion of DP lost from either soil or manure to the total quantity of $\mathrm{P}$ lost given the relative proportions of DP within the APLE model. When P Indices contain appropriately weighted contributing factors, management practices can be targeted to the $\mathrm{P}$ loss pathway responsible for the majority of $\mathrm{P}$ loss, thereby maximizing the effectiveness of conservation efforts.

\section{Total Surface P Loss}

The initial comparison between comp-PSI score and TP loss predicted by APLE for the theoretical dataset generated a data cloud with a general linear trend and a high correlation $\left(r=0.81^{* * *}\right.$, Fig. 5a). Despite the high correlation, there was low sensitivity in the comp-PSI, meaning as the comp-PSI scores increased up to $\sim 2500$ and estimated TP loss remained below $\sim 5 \mathrm{~kg} \mathrm{ha}^{-1}$. Moreover, the high correlation was likely due to large sample size of the theoretical dataset, as well as the generally high correlation between the comp-PSI particulate component and APLE particulate P loss, as both components were calculated similarly. The modifications made to the comp-PSI equation, in addition to the calculated weighting factors, increased the correlation of PMT-2 and modeled TP loss ( $r=0.91^{* * *}$, Fig. 5b). The modifications and weighting factors also alleviated the cluster of fields with low modeled P loss and high comp-PSI score. The insets of Fig. 5 indicated an improved correlation $\left(r=0.51^{* * *}\right.$ vs. $0.84^{* * *}$, Fig. 5) between PMT-2 and APLE, as well the slope of the regression line approaching one, when focusing on data points with comp-PSI scores $<2500$. This indicated increased sensitivity in PMT-2 versus comp-PSI and a more similar increase in magnitude of PMT-2 scores as modeled TP increased.

Generally, particulate P loss comprises the greatest proportion of TP lost from agricultural fields (Sharpley et al., 2000), and the majority of modeled TP loss was particulate P for $77 \%$ of the fields in the theoretical dataset. For the PMT-2, the weighting factors for the P loss components were calculated
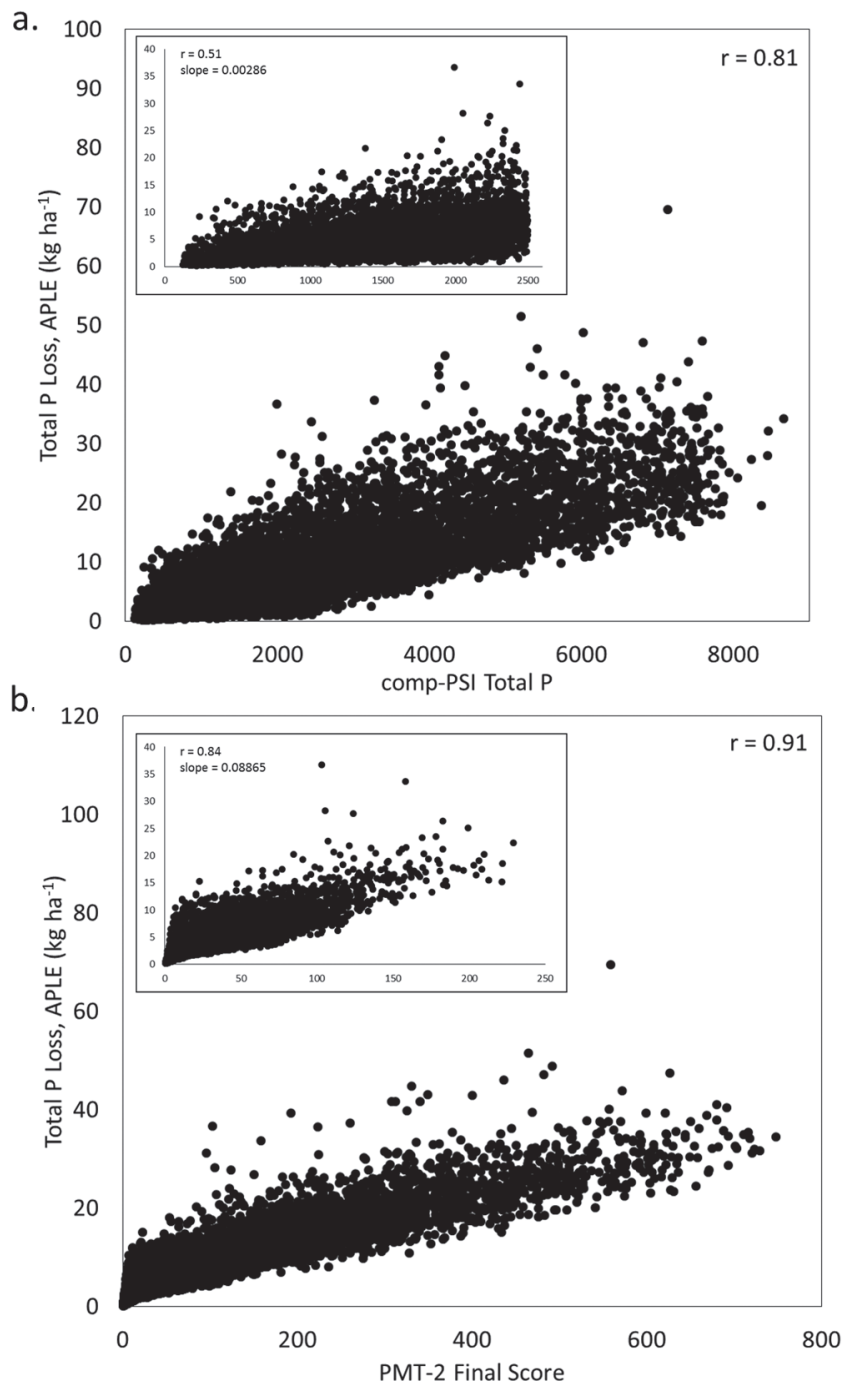

Fig. 5. Comparison of total phosphorus (P) loss in $\mathrm{kg} \mathrm{ha}^{-1}$ as estimated by Annual P Loss Estimator (APLE) with (a) total score for the component version of the Maryland P Site Index (comp-PSI) and (b) P Management Tool 2 (PMT-2) for fields in the theoretical dataset ( $n=10249$ ). Insets include a subset of data points with comp-PSI score $<2500(n=6684)$. Correlations are significant at $P<0.0001$.

based on relative contribution of the different $P$ loss pathways within the APLE model, instead of being determined by best professional judgment. This gives the end user confidence in the relative proportions of the P loss components within the PMT-2 final score.

\section{Verification of PMT-2 Using Empirical Data}

The final equation for the PMT-2 is presented in Eq. [5]:

PMT-2 = ParticulateP + SoilDP + Manure DP

where

Particulate $\mathrm{P}=0.154 \times($ RUSLE $\times 2.24) \times$ FIV

SoilDP $=0.67 \times($ Runoff $\times 0.01) \times\left(0.0259 \times \mathrm{DPS}_{\mathrm{M} 3}\right) \times \mathrm{SM}$

ManureDP $=1.11 \times(\text { Runoff } / \text { Rainfall })^{1.25} \times$ manure $_{2} \mathrm{O}_{5}$

$$
\times\left(\mathrm{WEP} \% \times \mathrm{AM}_{\mathrm{v}, 2}\right) \times \mathrm{AM} \times \text { Timing }
$$

where Runoff was annual runoff in $\mathrm{mm}$; SM was the soil management factor, with possible values of 0.8 and 1; Runoff/ Rainfall was the ratio of runoff $(\mathrm{mm})$ to rainfall $(\mathrm{mm})$; and 
Timing was the timing of amendment application factor, with possible values of 0.8 and 1 .

The empirical dataset was used to verify the relationship observed between comp-PSI and modeled P loss data for the theoretical dataset. Although the correlation between comp-PSI final score and estimated total $\mathrm{P}$ loss for the empirical dataset was strong $\left(r=0.78^{* * *}\right.$, Fig. $\left.6 \mathrm{a}\right)$, the correlation coefficient increased when PMT-2 was compared with modeled total P loss $\left(r=0.91^{* * *}\right.$, Fig. 6b). For each P loss pathway component of the comp-PSI, the modifications resulted in high correlation coefficients between $\mathrm{P}$ loss components of PMT-2 and their corresponding APLE output for the empirical dataset (Supplemental Fig. S1-S3).

\section{Implication of Present Work}

The methods presented here build on a method originally introduced by Bolster et al. (2012), who demonstrated successful improvements to the Kentucky P Index through evaluation against APLE (Bolster et al., 2014), and the present work included additional modifications specific to conditions in Maryland. First, we created a theoretical dataset to ensure consistency of conditions within each simulated field. Next, we took this evaluation as an opportunity to modify variables within the MD-PSI components. Some of the modifications made to the MD-PSI equation included removal of categorical variables when possible and the use of variables from APLE. Certain variables were included in PMT-2 to encourage specific management practices, which did not have a direct analog in APLE. Nonetheless, this method allowed these management factors to be evaluated for agreement with modeled $\mathrm{P}$ loss. Although more complex, process-based P loss models have been used to evaluate P Indices in other states (Bhandari et al., 2016; Forsberg et al., 2017), the present work demonstrated the use of a user-friendly empirical model to estimate P loss and evaluate a P Index. These methods, including the development of a theoretical dataset and the collection of an empirical dataset, can be easily applied in other states where there is motivation to update an existing P Index but expertise in the use of complex, process-based models may be absent. We have demonstrated that our methods can be used to modify a P Index and increase correlation between $\mathrm{P}$ Index output and modeled P loss data.

If using the method demonstrated here, P Index developers should take care that models employed are tested against measured P loss data, as has been done for APLE. Nonetheless, whether using measured or modeled P loss data, P Index evaluation is limited to a general agreement in direction between $\mathrm{P}$ Indices and $\mathrm{P}$ loss data and similar magnitude of increase in $\mathrm{P}$ Index values as P loss is increased. Moreover, although we used a model due to scarcity of measured P loss data, in some instances modeled data were lacking as well. For example, APLE does not contain a subsurface DP loss pathway, precluding evaluation of this component of PMT-2. Nonetheless, subsurface DP loss is a dominant P loss pathway for ditch drained fields in the coastal plain of the Delmarva Peninsula (Vadas et al., 2007), and methods should be developed to complete evaluation of this component. There are a number of shared input variables between APLE and PMT-2, meaning correlations between the two models may be better than correlations between PMT-2 and measured P loss data. Phosphorus Index development and modification is advancing, and the method presented here represents one means for developing greater confidence in final P Index scores.
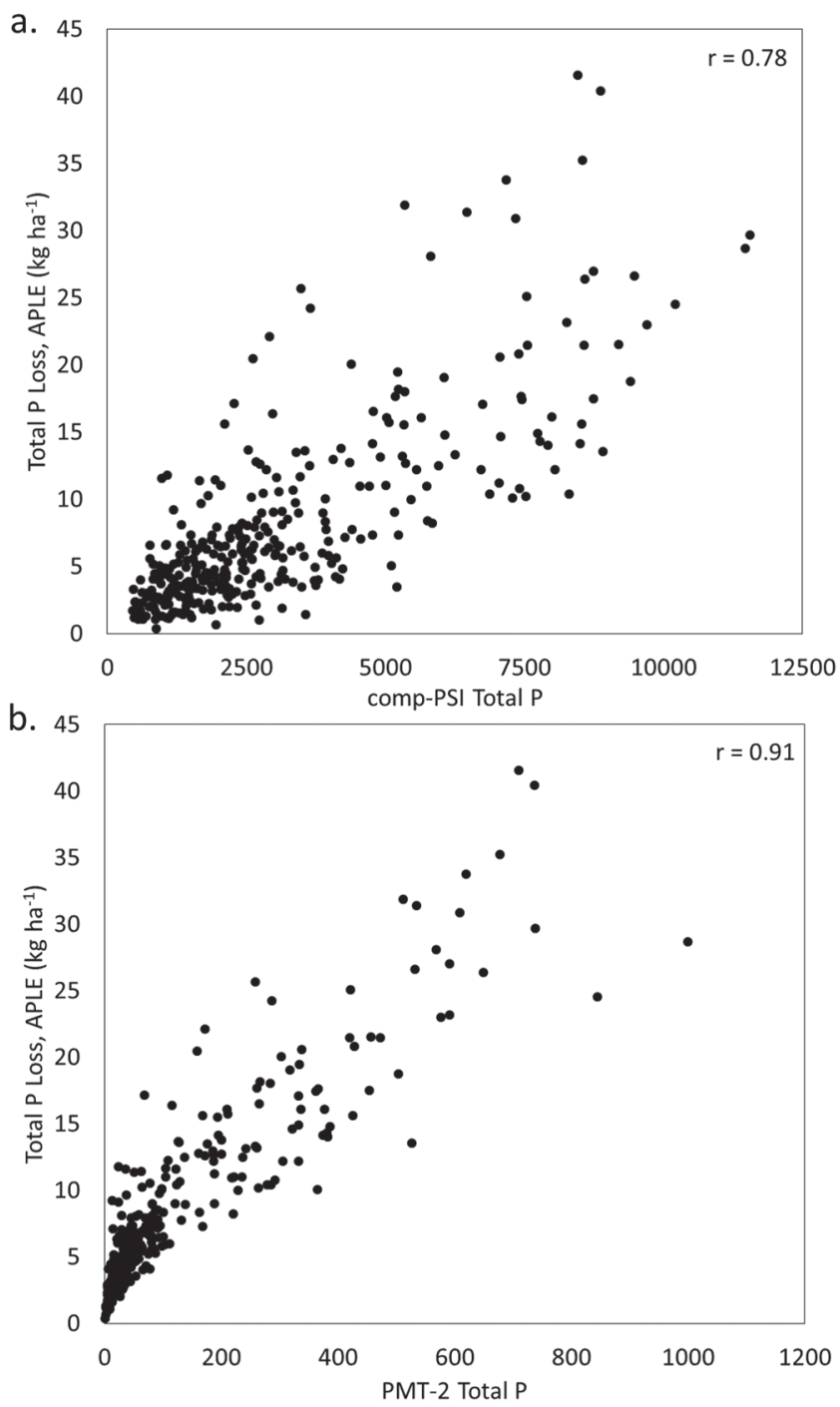

Fig. 6. Comparison of total phosphorus (P) loss in $\mathrm{kg} \mathrm{ha}^{-1}$ as estimated by Annual P Loss Estimator (APLE) with (a) total P score for the component version of the Maryland P Site Index (comp-PSI) and (b) P Management Tool 2 (PMT-2) for fields in the empirical dataset $(n=$ 382 ) identified by dominant $P$ loss pathway. Correlations are significant at $P<0.0001$.

\section{References}

Angle, J.S., G. McClung, M.S. McIntosh, P.M. Thomas, and D.C. Wolf. 1984. Nutrient losses in runoff from conventional and no-till corn watersheds. J. Environ. Qual. 13:431-435. doi:10.2134/ jeq1984.00472425001300030021x

Bhandari, A.B., N.O. Nelson, D.W. Sweeney, C. Baffaut, J.A. Lory, A. Senaviratne et al. 2016. Calibration of the APEX model to simulate management practice effects on runoff, sediment, and phosphorus loss. J. Environ. Qual. doi: $10.2134 /$ jeq2016.07.0272

Bolster, C.H. 2011. A critical evaluation of the Kentucky Phosphorus Index. J. Ky. Acad. Sci. 72:46-58.

Bolster, C.H., A. Forsberg, A. Mittelstet, D.E. Radcliffe, D.E. Storm, J. RamirezAvila et al. 2017. Comparing an annual and daily time-step model for predicting field-scale phosphorus loss. J. Environ. Qual. doi:10.2134/ jeq2016.04.0159

Bolster, C.H., T. Horvath, B.D. Lee, S. Mehlhope, S. Higgins, and J.A. Delgado. 2014. Development and testing of a new phosphorus index for Kentucky. J. Soil Water Conserv. 69:183-196. doi:10.2489/jswc.69.3.183

Bolster, C.H., P.A. Vadas, A.N. Sharpley, and J.A. Lory. 2012. Using a phosphorus loss model to evaluate and improve Phosphorus Indices. J. Environ. Qual. 41:1758-1766. doi:10.2134/jeq2011.0457

Boynton, W.R. 2000. Impact of nutrient inflows on Chesapeake Bay. In: A.N. Sharpley, editor Agriculture and phosphorus management. Lewis Publishers, Boca Raton, FL. p. 23-40. 
Coale, F.J., J.T. Sims, and A.B. Leytem. 2002. Accelerated deployment of an agricultural nutrient management tool. J. Environ. Qual. 31:1471-1476. doi:10.2134/jeq2002.1471

Djodjic, F. and L. Bergström. 2005. Conditional phosphorus index as an educational tool for risk assessment and phosphorus management. Ambio 34:296-300. doi:10.1579/0044-7447-34.4.296

Edgell, J., D.L. Osmond, D.E. Line, G.D. Hoyt, J.M. Grossman, and E.M. Larsen. 2015. Comparison of surface water quality and yields from organically and conventionally produced sweet corn plots with conservation and conventinoal tillage. J. Environ. Qual. 44:1861-1870. doi:10.2134/ jeq2015.02.0074

Forsberg, A., D.E. Radcliffe, C.H. Bolster, A. Mittelstet, D.E. Storm, and D.L. Osmond. 2017. Evaluation of the TBET model for potential improvement of Southern P Indices. J. Environ. Qual. doi:10.2134/jeq2016.06.0210

Gburek, W.J., and A.N. Sharpley. 1998. Hydrologic controls on phosphorus loss from upland agricultural watersheds. J. Environ. Qual. 27:267-277. doi:10.2134/jeq1998.00472425002700020005x

Gburek, W.J., A.N. Sharpley, L. Heathwaite, and G.J. Folmar. 2000. Phosphorus management at the watershed scale: A modification of the phosphorus index. J. Environ. Qual. 29:130-144. doi:10.2134/ jeq2000.00472425002900010017x

King, K.W., M.R. Williams, M.L. Macrae, N.R. Fausey, J. Frankenberger, D.R. Smith et al. 2014. Phosphorus transport in agricultural subsurface drainage: A review. J. Environ. Qual. 44:467-485. doi:10.2134/jeq2014.04.0163

Kleinman, P.J.A., A.L. Allen, B.A. Needelman, A.N. Sharpley, P.A. Vadas, L.S. Saporito et al. 2007. Dynamics of phosphorus transfers from heavily manured coastal plain soils to drainage ditches. J. Soil Water Conserv. 62:225-235.

Lemunyon, J., and R. Gilbert. 1993. The concept and need for a phosphorus assessment tool. J. Prod. Agric. 6:483-486. doi:10.2134/jpa1993.0483

McGrath, J.M. 2006. SFM-4 converting among soil test analyses frequently used in Maryland. Univ. of Maryland Ext., College Park, MD.

Mehlich, A. 1984. Mehlich 3 soil test extractant: A modification of Mehlich 2 extractant. Commun. Soil Sci. Plant Anal. 15:1409-1416. doi:10.1080/00103628409367568

Nelson, N.O., and A.L. Shober. 2012. Evaluation of Phosphorus Indices after twenty years of science and development. J. Environ. Qual. 41:1703-1710. doi:10.2134/jeq2012.0342

Osmond, D.L., A. Sharpley, C. Bolster, M. Cabrera, S. Feagley, B. Lee et al. 2012. Comparing Phosphorus Indices from twelve Southern U.S. states against monitored phosphorus load from six prior Southern studies. J. Environ. Qual. 41:1741-1749. doi:10.2134/jeq2012.0013

PRISM Climate Group. 2015. PRISM climate data. Northwest Alliance for Computational Science and Engineering. http://www.prism.oregonstate. edu/ (accessed 20 Apr, 2015).

Renard, K.G., G.R. Foster, G.A. Weesies, D. McCool, and D. Yoder. 1997. Predicting soil erosion by water: A guide to conservation planning with the revised universal soil loss equation (RUSLE). Agric. Handb. 703. USDA, Washington, DC.
SAS Institute. 2009. SAS/STAT user's guide. SAS Inst., Cary, NC.

Sharpley, A., D.B. Beegle, C. Bolster, L. Good, B.C. Joern, Q.M. Ketterings et al. 2011. Revision of the 590 nutrient management standard: SERA-17 recommendations. Southern Coop. Ser. Bull. 412. SERA-IEG-17, Virginia Tech. University, Blacksburg, VA

Sharpley, A., D.B. Beegle, C. Bolster, L. Good, B.C. Joern, Q.M. Ketterings et al. 2012. Phosphorus Indices: Why we need to take stock of how we are doing. J. Environ. Qual. 41:1711-1719. doi:10.2134/jeq2012.0040

Sharpley, A.N., B. Foy, and P. Withers. 2000. Practical and innovative measures for the control of agricultural phosphorus losses to water: An overview. J. Environ. Qual. 29:1-9. doi:10.2134/jeq2000.00472425002900010001x

Sharpley, A.N., J.L. Weld, D.B. Beegle, P.J.A. Kleinman, W.J. Gburek, P.A. Moore et al. 2003. Development of phosphorus indices for nutrient management planning strategies in the US. J. Soil Water Conserv. 58:137-152.

Sims, J.T., R.O. Maguire, A.B. Leytem, K.L. Gartley, and M.C. Pautler. 2002. Evaluation of Mehlich 3 as an agri-environmental soil phosphorus test for the Mid-Atlantic United States of America. Soil Sci. Soc. Am. J. 66:20162032. doi:10.2136/sssaj2002.2016

USDA-SCS. 1972. Chapter 10: Estimation of direct runoff from storm rainfall. Part 630 hydrology national engineering handbook. USDA, Soil Conserv. Serv., Washington, DC.

Vadas, P.A. 2012. APLE theoretical documentation version 2.3. US Dairy Forage Res. Center, USDA-ARS, Madison, WI.

Vadas, P.A., L.W. Good, P.A. Moore, and N. Widman. 2009. Estimating phosphorus loss in runoff from manure and fertilizer for a phosphorus loss quantification tool. J. Environ. Qual. 38:1645-1653. doi:10.2134/ jeq2008.0337

Vadas, P.A., B.E. Haggard, and W.J. Gburek. 2005a. Predicting dissolved phosphorus in runoff from manured field plots. J. Environ. Qual. 34:13471353. doi: $10.2134 /$ jeq2004.0424

Vadas, P.A., P.J.A. Kleinman, A.N. Sharpley, and B.L. Turner. 2005b. Relating soil phosphorus to dissolved phosphorus in runoff: A single extraction coefficient for water quality modeling. J. Environ. Qual. 34:572-580. doi:10.2134/jeq2005.0572

Vadas, P.A., M.S. Srinivasan, P.J.A. Kleinman, J.P. Schmidt, and A.L. Allen. 2007. Hydrology and groundwater nutrient concentrations in a ditch-drained agroecosystem. J. Soil Water Conserv. 62:178-188.

Westerman, P.W., L.D. King, J.C. Burns, G.A. Cummings, and M.R. Overcash. 1987. Swine manure and lagoon effluent applied to a temperate forage mixture: II. Rainfall runoff and soil chemical properties. J. Environ. Qual. 16:106-112. doi:10.2134/jeq1987.00472425001600020003x

Westerman, P.W., M.R. Overcash, R.O. Evans, L.D. King, J.C. Burns, and G.A. Cummings. 1985. Swine lagoon effluent applied to 'Coastal' bermudagrass: III. Irrigation and rainfall runoff. J. Environ. Qual. 14:22-25. doi:10.2134/jeq1985.00472425001400010004x 